\title{
Familial complex chromosome rearrangement ascertained by in situ hybridisation
}

\author{
C Fuster, L Miguez, R Miró, M A Rigola, A Perez, J Egozcue
}

\begin{abstract}
A complex familial chromosome translocation has been ascertained by combining classical cytogenetics and CISS (chromosomal in situ suppression). Cytogenetic analysis of a chorionic villus sample with $G$ banding showed a $47, X X,-2$, $+\operatorname{der}(2) t(2 ; 22),+\operatorname{der}(22) t(2 ; 22)$ karyotype. Analysis of peripheral blood lymphocytes from the parents by $G$ banding and CISS showed a more complex translocation in the father: $46, X Y,-2,-11,-22,+\operatorname{der}(2)$ $t(2 ; 11)(q 13 ; q 23),+\operatorname{der}(11) t(11 ; 22) \quad(q 23 ;$ q11.2), $+\operatorname{der}(22) \quad t(2 ; 22) \quad$ (q13;q11.2). Definitive analysis of cultured amniotic fluid cells showed a double partial trisomy of chromosomes 11 and 22. The couple decided to continue the pregnancy. The fetal karyotype was confirmed at birth. Clinical abnormalities present in our patient were typical of an unbalanced 11;22 translocation. Our findings confirm that chromosome painting techniques allow a better characterisation of complex chromosome rearrangements which may be difficult to detect in $G$ banded karyotypes.

(F Med Genet 1997;34:164-166)
\end{abstract}

Keywords: prenatal diagnosis; complex chromosomal translocation; chromosomal in situ hybridisation.

Departament de Biologia Cel.lular i Fisiologia, Unitat de Biologia, Facultat de Medicina, Universitat Autònoma de

Barcelona, 08193

Bellaterra, Barcelona,

Spain

C Fuster

R Miró

M A Rigola

J Egozcue

Diagnóstic Prenatal, Anexo Clínica Quirón, Barcelona, Spain

L Miguez

Hospital Central La Alianza, Barcelona, Spain

A Perez

Correspondence to: Dr Fuster

Received 23 January 1996 Revised version accepted for publication 14 August 1996
Many chromosomal rearrangements may go unnoticed when using classical banding techniques, especially if they involve small fragments or fragments with similar or identical banding patterns. The characterisation of such anomalies is extremely important in prenatal diagnosis and in patients with congenital malformations. In some cases, a given chromosome anomaly may be difficult to characterise in amniocytes or in chorionic villus samples even if a balanced reorganisation is known to be present in one of the parents. ${ }^{1-3}$ Often, these problems may be solved by using in situ hybridisation techniques that allow characterisation of subtle rearrangements ${ }^{4-6}$ and detection of some de novo structural anomalies. ${ }^{7-9}$

Here, we report a complex chromosome rearrangement not fully resolved by chromosome banding of chorionic villus cells. Chromosome painting disclosed an unbalanced translocation involving three chromosomes, inherited from the balanced, carrier father.

\section{Case report}

A 31 year old woman requested a prenatal diagnosis when she was in the 11 th week of pregnancy. Previously, she had had three spontaneous abortions and a phenotypically normal $\bar{\omega}$ son. Cytogenetic analysis of chorionic villus $\vec{D}$ cells after Wright's $G$ banding showed an unbalanced translocation that was initially o diagnosed as a $47, \mathrm{XX},-2,+\operatorname{der}(2) \mathrm{t}(2 ; 22)$, 우 $+\operatorname{der}(22) t(2 ; 22)$

Analysis of peripheral blood lymphocytes from the parents showed the presence in the father of the same derivative chromosomes $2 \stackrel{\vec{\omega}}{\omega}$ and 22. However, the higher degree of resolution obtained in $\mathrm{G}$ banded peripheral blood preparations suggested that the bands in der(2) did not correspond to chromosome 22 , 은 and indicated the possible presence of a more complex translocation.

Chromosomal in situ suppression (CISS) hybridisation using DNA libraries for chromosomes 2 and 22 (Cambio, Cambridge) labelled with biotin was performed on peripheral blood preparations from the father following instruc- . tions from the supplier. Detection of hybridisation was performed using the immunoperoxidase technique as described by Pérez-Losada et al. ${ }^{10}$ At least 10 metaphases per probe were

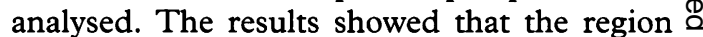
distal to $2 \mathrm{q} 13$ was translocated to $22 \mathrm{q} 11.2$, $\overrightarrow{\overline{0}}$ while the region distal to $22 \mathrm{q} 11.2$ was not 3 translocated to chromosome 2 , but to a chromosome from group $\mathrm{C}$. The reassessment of $\mathrm{G}$ banded preparations suggested the possi- $\overline{\overline{3}}$ ble involvement of chromosome 11. A CISS hybridisation was then performed with a DNA 3 library for that chromosome pair, which implicated chromosome 11 in this complex translocation. The three derivative chromosomes 0 resulting from the translocation were characterised as $\operatorname{der}(2) \mathrm{t}(2 ; 11)(\mathrm{q} 13 ; \mathrm{q} 23), \operatorname{der}(11)$ 음 $\mathrm{t}(11 ; 22)$ (q23;q11.2), and $\operatorname{der}(22) \mathrm{t}(2 ; 22) \mathrm{N}$ (q13;q11.2) (fig1)

Subsequent classical cytogenetic and in situ $\mathrm{O}$ hybridisation (CISS) analysis of amniocytes $\tilde{\omega}$ allowed us to reinterpret the karyotype of the fetus as $47, \mathrm{XX} .-2,+\operatorname{der}(2) \mathrm{t}(2 ; 11)(\mathrm{q} 13 ; \mathrm{q} 23)$, $+\operatorname{der}(22) \mathrm{t}(2 ; 22)$ (q13; 111.2$)$. The presence of $\mathbb{\Phi}$ two normal chromosomes 11 and 22 in ? addition to the derivative chromosomes ${ }^{\circ}$ resulted in double partial trisomies of $\frac{\vec{D}}{\mathbb{D}}$ chromosomes 11 and 22 (figs 2 and 3). $\frac{9}{8}$

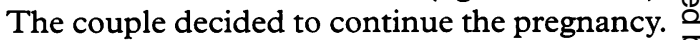
Cytogenetic study of the neonate verified the fetal karyotype and no mosaicism was found in 0 73 metaphases analysed. She was born at term with a head circunference of $34 \mathrm{~cm}$, length 51 흘 $\mathrm{cm}$, and weight $2840 \mathrm{~g}$. The most important? clinical features since the child was born have been retarded physical growth, obvious psychomotor retardation, muscular hypotonia, 

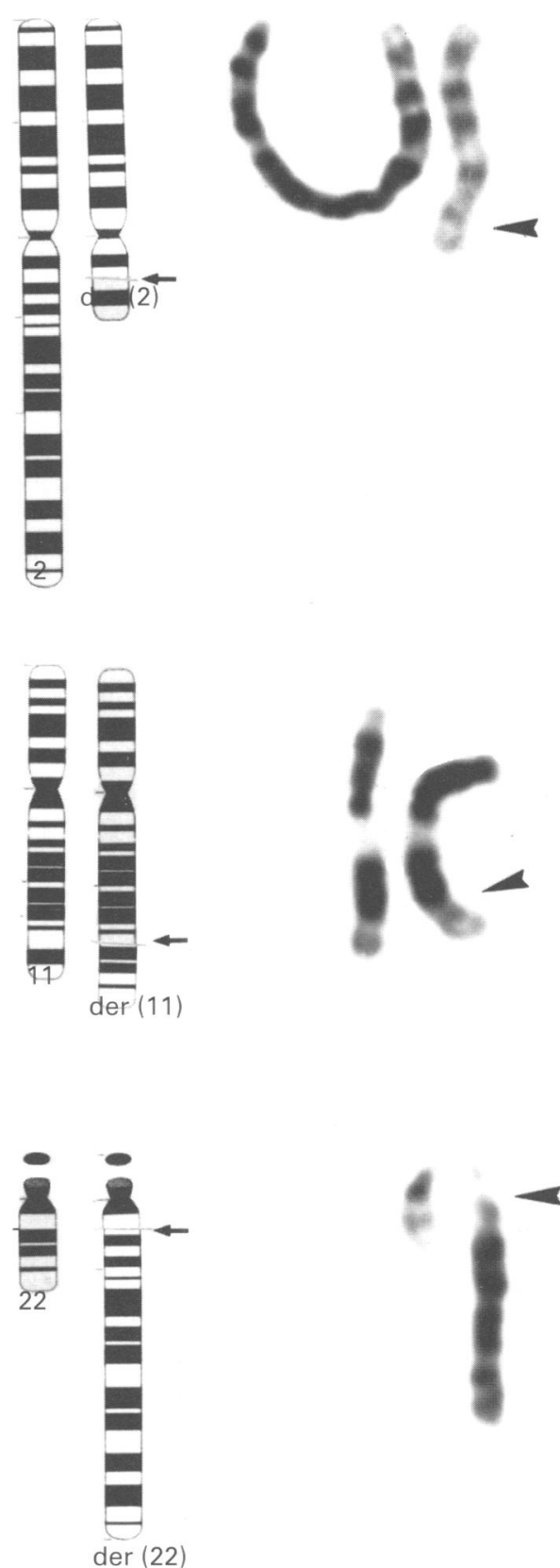

Figure $1 G$ banded partial karyotype from the father and $G$ banded diagram of the chromosomes involved in the translocations: $\operatorname{der}(2) t(2 ; 11)(q 13 ; q 23)$, $\operatorname{der}(11) t(11 ; 22)(q 23, q 11.2), \operatorname{der}(22) t(2 ; 22)$

(q13;q11.2). Arrowheads indicate the three derivative chromosomes.

talipes calcaneovarus, congenital heart disease (intra-auricular connection), cleft palate, broad nose resulting from a short septum, and preauricular pits. The child is now 14 months old and her parents refuse further investigation.

Chromosome analysis of the different members of the family showed that the complex balanced translocation was also present in the paternal gandmother (fig 4). Other members of this family were not available for cytogenetic study.
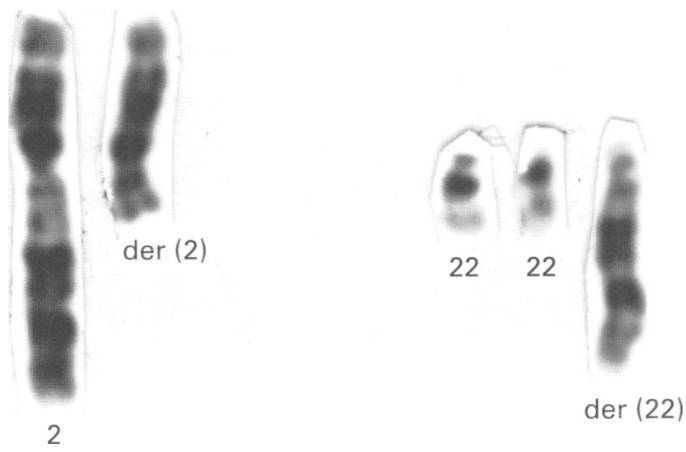

Figure $2 G$ banded partial karyotype from an amniocyte showing normal and derivative chromosomes
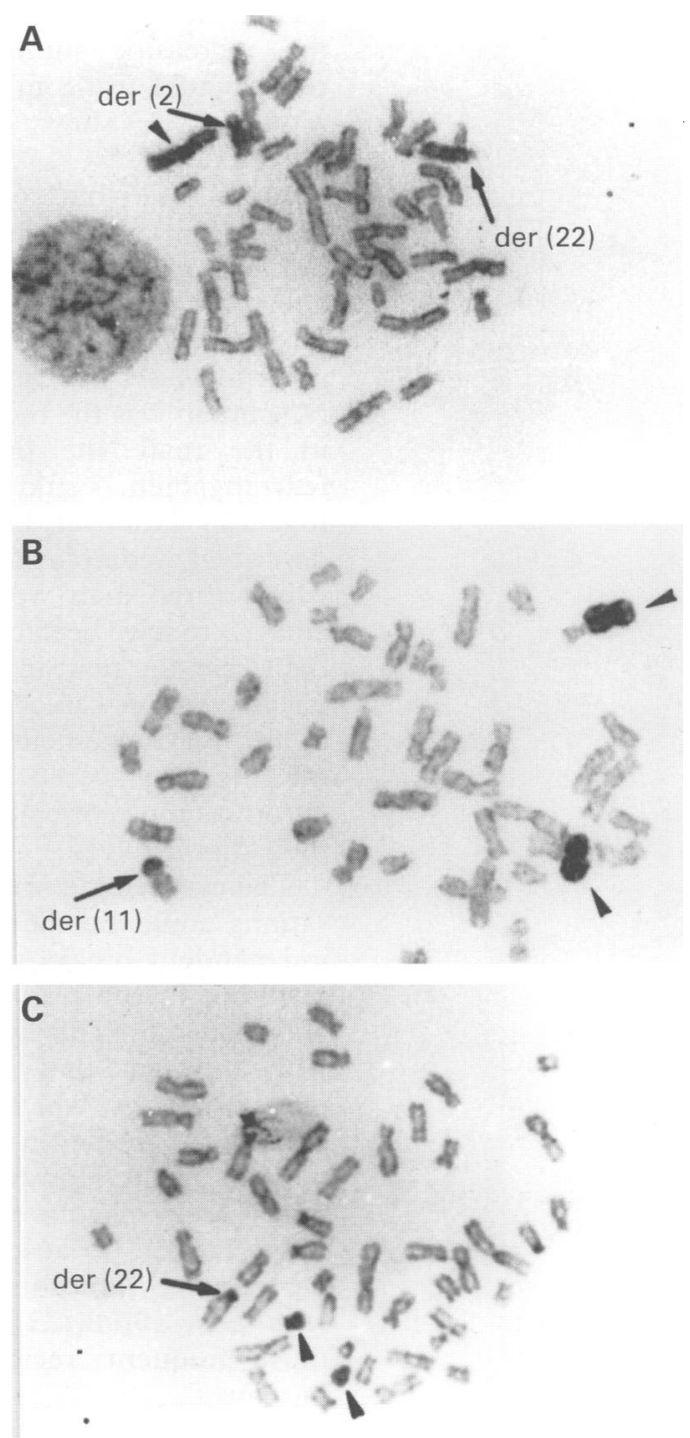

Figure 3 CISS hybridisation on amniocyte metaphases using libraries from chromosome $2(A)$, chromosome 11 $(B)$, and chromosome $22(C)$. In $(A)$ the arrowhead points to the normal chromosome 2 and the arrows to $\operatorname{der}(2)$ and $\operatorname{der}(22)$; in (B) arrowheads point to the two normal chromosomes 11 and the arrow to $\operatorname{der}(2)$; in (C) arrowheads point to the two normal chromosomes 22 and the arrow to der(22).

\section{Discussion}

Our results, as well as those of other authors, ${ }^{4-6}$ emphasise the need to combine different approaches in chromosome rearrangements not resolved by standard cytogenetic techniques. The most simple combination includes painting, to identify the chromosome frag- 


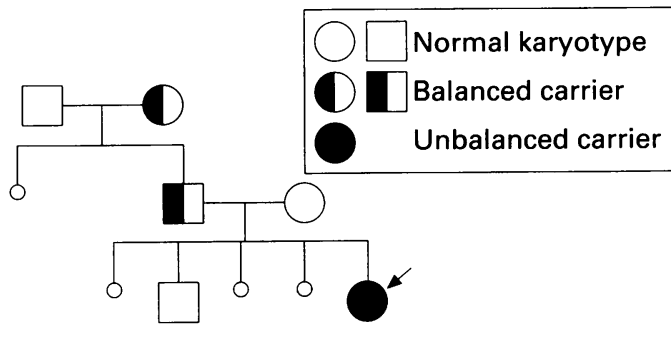

Figure 4 Pedigree of the family.

ments involved in the reorganisation, and high resolution $G$ banding to identify the breakpoints. ${ }^{11} 12$ In fact, the incidence of subtle and complex rearrangements is probably much higher than previously thought, ${ }^{13}$ as shown by the increasing number of cases that are re-evaluated using in situ hybridisation techniques to show previously unnoticed anomalies. ${ }^{1415}$

About one third of complex chromosome rearrangements are inherited ${ }^{1617}$ and result in duplications and deficiencies responsible for abortions or congenital malformations in the offspring. Daniel et $a l^{18}$ observed that in most inherited cases the carrier of the balanced rearrangement was the mother, and suggested that in the male the presence of a balanced rearrangement could interfere with spermatogenesis. However, Farrell et $a l^{19}$ have recently described a complex familial rearrangement in which three men were inferred by pedigree analysis to have been carriers, indicating that in their case the rearrangement allowed for male fertility. In our case, the paternal transmission of the rearrangement supports the idea that male fertility would depend on the type of chromosome reorganisation and on the chromosomes involved.

The cytogenetic origin of complex reorganisations could be the result of three or more independent breaks that rejoined at random, resulting in the production of the derivative chromosomes. This hypothesis is in agreement with the fact that two thirds of complex reorganisations, which may affect as many as four ${ }^{14}$ or even seven chromosomes, ${ }^{20}$ are de novo in origin. However, in our case the complex $\mathrm{t}(2 ; 11)$ may have originated from a previous $t(11 ; 22)$, because the breakpoints in the derivative chromosomes 11 and 22 coincide with those of $t(11 ; 22)$ (q23; q1 1.2) which is the most frequent reciprocal translocation in humans. ${ }^{21}$

The only viable patients with unbalanced $11 ; 22$ translocations are trisomic for the centromeric segment of 22 (approximately 22pter-q11) and for the distal segment of 11 (approximately 11q23-qter). ${ }^{22}$ In our case the same chromosome (added to 2q) segments are implicated in the partial trisomy and the clinical abnormalities are coincidentally more characteristic of the unbalanced $11 ; 22$ translocation phenotype. ${ }^{2123-26}$

The present observation substantiates the effectiveness of the combined use of $\mathrm{G}$ banding and chromosome painting techniques in raising the quality of prenatal diagnosis and disclosing rearrangements not resolved by standard cytogenetics.

We acknowledge the financial support given by CIRIT to the Cell Biology Unit (GRQ93-2025 and GRQ93-2097).

1 Smart RD, Retief AE, Overhauser J. Confirmation of a balanced chromosomal translocation using molecular techniques. Prenat Diagn 1989;9:505-13.

2 Taviaux S, Moncla A, Girauld F, Demaille J, Mattei JF, Mattei MG. Diagnostic de remaniements chromosomiques de petite taille par la cytogénétique moleculaire. Ann Genet (Paris) 1989;32:204-10.

3 Callen DF, Baker E, Eyre HJ, Chernos JE, Bell JA, Sutherland GR. Reassessment of two apparent deletions of chroland $16 \mathrm{p}$ to an ins $(11 ; 16)$ and $\mathrm{a} t(1 ; 16)$ by chromosome painting. Ann Genet (Paris) 1990;33:219-21.

4 Speleman F, Van Roy N, Wiegant J, et al. Detection of subtle reciprocal translocation by fluorescence in situ hybridization. Clin Genet 1992;41:169-174.

5 Sullivan SA, Leana-Cox J, Schwartz S. Clarification of subtle reciprocal rearrangements using fluorescence in situ hybridization. Am ₹ Med Genet 1993;47:223-30

6 Delaroche I, Sabani M, Calabrese G, Mingarelli R, Palka G, Dallapiccola B. Fetal translocation between chromosomes 2,18 and 21 resolved by FISH. Prenat Diagn 1995;15:27881 .

7 Van Opstal D, Eussen HJ, Van Hemel JO, Sachs ES. Application of fluorescent in situ hybridization for "de novo" anomalies in prenatal diagnosis. Prenat Diagn 1993;13:82532 .

8 Takano T, Yamonouchi Y, Kawashima S, et al. 11q trisomy detected by fluorescence in situ hybridization. Clin Genet 1993;44:324-8.

9 DuPont BR, Huff RW, Ridgway LE, Stratton RF, Moore 윽 CM. Prenatal diagnosis of partial trisomy $1 \mathrm{q}$ using fluorescent in situ hybridization. Am $\mathcal{F}$ Med Genet 1994;50:21-7.

10 Pérez-Losada A, Wessman M, Tiainen M, et al. Trisomy 12 in chronic lymphocytic leukemia: an interphase cytogenetic study. Blood 1991;78:775-9.

11 Savage JRK, Simpson P. On the scoring of FISH-"painted" chromosome-type exchange aberrations. Mutat Res 1994; 307:345-53.

12 Tucker JD, Morgan WF, Awa AA, et al. A proposed system for scoring structural aberrations detected by chromosome painting. Cytogenet Cell Genet 1995;68:211-21.

13 Wakita Y, Narahara K, Tsuji K, et al. De novo complex chromosome rearrangement in identical twins with multiple congenital anomalies. Hum Genet 1992;88:596-8.

14 Hertz B, Brandt CA, Petersen MB, et al. Application of molecular and cytogenetic techniques to the detection of a de novo unbalanced $\mathrm{t}(1 \mathrm{q} ; 21 \mathrm{q})$ in a patient previously diagnosed as having monosomy 21 . Clin Genet 1993;44:8994.

15 Ohta T, Tohma T, Soejima H, et al. The origin of cytologically unidentifiable chromosome abnormalities: six cases ascertained by targeted chromosome-band painting. Hum Genet 1993;92:1-5.

16 Kleczkowska A, Fryns JP, Van den Berghe H. Complex chromosomal rearrangements and their genetic consechromosomal rearrangements and their

7 quences. f Genet Hum 1982;30:199-214. Kausch $\mathrm{K}$, Haaf $\mathrm{T}$, Kohler $\mathrm{J}$, woman with multiple miscarsomal rearrangement in a woman with

18 Daniel A, Hook EB, Wulf G. Collaborative U.S.A. data on prenatal diagnosis for parental carriers of chromosome 을 prenatal diagnosis for parental carriers of chromosome ed. The cytogenetics of mammalian autosomal rearrangements. New York: Alan R Liss, 1988:101-2.

19 Farrell SA, Summers AM, Gardner HA, Uchida IA. Balanced complex chromosome rearrangement ascer- 0 tained through prenatal diagnosis. Am $\mathcal{f}$ Med Genet 1994;52:360-1.

20 Lurie IW, Wulfsberg EA, Prabhakar G, Rosenblum-Vos LS, O Supovitz KR, Cohen MM. Complex chromosomal rearran ements: some breakpoints may have cellular adaptive significance Clin Genet 1994;46:244-7.

21 Fraccaro $M$, Lindsten J, Ford CE, Iselius $L$. The $11 \mathrm{q} ; 22 \mathrm{q} \omega$ translocation: a European collaborative analysis of 43 cases. translocation: a European coll

22 Schinzel A, Schmid W, Auf der Maur P, et al. Incomplete trisomy 22. I. Familial 11/22 translocation with 3:1 meiotic $\mathbb{D}$ trisomy 22. I. Familial 11/22 translocation with $3: 1$ meiotic $\mathbb{D}$ disjunction. Delineation of a common clinical picture and report of nine new cases from six families. Hum Genet
1981;56:249-62.

23 Zackai E, Emanuel B. Site-specific reciprocal translocation, $t(11 ; 22)$ (q23;q11) in several unrelated families with $3: 1 \frac{\mathbb{D}}{\Omega}$ meiotic disjuction. Am $\mathcal{F}$ Med Genet 1980;7:507-21.

24 Schinzel A. Catalogue of unbalanced chromosome aberrations in man. Berlin: Walter de Gruyter, 1983:200-2.

25 Iselius L, Lindstein J, Aurias A, et al. The 11q;22q translocation: a collaborative study of 20 new cases and $\bigcirc$ analysis of 110 families. Hum Genet 1983;64:343-55.

26 Blancato JK, Eglinton G, George J, Benkendorf J, Pinkert T, Meck J. Prenatal diagnosis of partial trisomy through in situ hybridization on amniocytes with whole chromosome and centromere-specific DNA probes. A case report. 7 Reprod Med 1995;40:537-9. 